\title{
El patrimonio industrial como dinamizador del territorio. El caso del ecomuseo La Farinera, en Castelló d'Empúries (Cataluña) ${ }^{1}$
}

\author{
Josep Maria Prat \\ Gemma Cànovas Valiente \\ Universitat Autònoma de Barcelona. Departament de Geografia \\ jmpratf@gmail.com \\ gemma.canovas@uab.cat
}

\section{Resumen}

En el actual marco postfordista, el turismo industrial es una opción turística que se está consolidando en nuestro país. Los ecomuseos son una de sus manifestaciones principales y engloban a un conjunto de elementos (territorio, patrimonio industrial, tareas y costumbres propias de la vida local) que ayudan a recuperar el patrimonio industrial, a veces abandonado y destruido, valorizándolo turísticamente y difundiendo una nueva cultura del desarrollo de la identidad territorial. Así, la memoria colectiva se convierte en el principal motor de los proyectos desarrollados con la participación de la comunidad local, aunque a veces los ecomuseos presentan importantes dificultades económicas. Éste es el caso del ecomuseo La Farinera, de Castelló d'Empúries (Girona), que, situado en una zona de gran afluencia turística, la Costa Brava, actúa como pequeña oferta complementaria turísticoformativa y, además, ayuda a la comunidad, puesto que refuerza su identidad y revaloriza su patrimonio industrial, cultural y social.

Palabras clave: patrimonio industrial; turismo industrial; ecomuseo; territorio; identidad.

Resum. El patrimoni industrial com a dinamitzador del territori. El cas de l'ecomuseu La Farinera, de Castelló d'Empúries (Catalunya)

Dins de l'actual entorn postfordista, el turisme industrial és una opció que s està consolidant en el nostre país. Els ecomuseus en són una de les manifestacions principals, ja que engloben un conjunt d'elements (territori, patrimoni industrial, tasques i costums propis de la vida local), de manera que no només valoritzen el patrimoni, sinó que també difonen una nova cultura del desenvolupament sostenible del territori, on la memòria col-lectiva es converteix en el motor principal d'uns projectes desenvolupats amb la participació activa

1. Este artículo se desarrolla en el marco del proyecto de investigación Turismo, territorio e identidad: procesos de revalorización de espacios y actividades en el medio rural español. Un análisis comparado de los casos de Cataluña, Galicia y Murcia, del Plan Nacional de I+D+i, financiado por el Ministerio de Ciencia e Innovación. Referencia: CSO2009-11793. 
de la comunitat local com a element vertebrador, encara que amb importants dèficits econòmics. Aquest és el cas de l'ecomuseu La Farinera, de Castelló d'Empúries (Girona), que, situat en una zona amb molta afluència turística, la Costa Brava, actua com una petita oferta educativoturística, complementària, però que ajuda a reforçar el sentiment de pertinença a una comunitat i a revaloritzar-ne el patrimoni industrial, cultural i social.

Paraules clau: patrimoni industrial; turisme industrial; ecomuseus; territori; identitat.

Résumé. Le patrimoine industriel comme un coup de pouce pour le pays: le cas de l'éco-musée La Farinera, à Castelló d'Empúries (Catalunya)

Dans le courant environnement post-fordiste, le tourisme industriel est une option qui est en train de se consolider dans notre pays. Les écomusées sont une de ses principales manifestations, englobant un ensemble d'éléments (territoire, patrimoine industriel, traditions de la vie locale), qui ne sont pas seulement le patrimoine mais aussi une nouvelle culture du développement durable du territoire, où la mémoire collective devient le principal moteur de certains projets développés avec la participation active de la communauté locale. C'est le cas de l'éco-musée La Farinera, de Castelló d'Empúries (Girona), situé dans la zone touristique de la Costa Brava, et qui s'agit comme une petite offre supplémentaire culturelle et touristique, et qui contribue à renforcer le sentiment d'appartenance à une communauté et à revitaliser son patrimoine industriel, culturel et social.

Mots clé: patrimoine industriel; industrie du tourisme; écomusées; territoire; identité.

Abstract. Industrial heritage as a boost for the country: The case of eco-museum The Farinera, in Castelló d'Empúries (Catalunya)

In the current post-fordist system, the industrial tourism is an option that is being consolidated in our country, sand the ecomuseums are one of its main manifestations, encompassing a set of elements (land, industrial heritage, duties and customs of local life), so that not only value the heritage, often abandoned and destroyed, but also spread a new culture of sustainable development of the territory, where the collective memory becomes the main driver of some projects developed with the active participation of the local community as the backbone. This is the case of eco-museum The Farinera, of Castelló d'Empúries (Girona), which, being located in an important touristic area, la Costa Brava, like as a small education-touristic offer, complementary, but it helps to reinforce the sense of belonging to a community and revitalize its industrial heritage, cultural and social.

Key words: industrial heritage; tourism industry; ecomuseum; territory; identity.

\section{Sumario}

Introducción El ecomuseo La Farinera,

Qué entendemos por ecomuseos y de Castelló d'Empúries patrimonio cultural Conclusiones

El turismo del patrimonio industrial Bibliografía como fenómeno dinamizador del territorio 


\section{Introducción}

En este artículo, se analiza cómo, a partir del turismo industrial y la creación de los ecomuseos en un territorio, se consigue dinamizar un destino. Los ecomuseos actúan como catalizadores y dinamizadores, junto con una labor pedagógica y de reforzamiento de la identidad local.

El artículo expone el marco teórico sobre la concepción de los ecomuseos y el turismo industrial, y presenta los factores que actúan como dinamizadores del territorio.

El caso concreto de estudio ha sido el ecomuseo La Farinera, actualmente el único ecomuseo que existe en Cataluña, y que se halla situado en la población gerundense de Castelló d'Empúries, en plena Costa Brava.

\section{Qué entendemos por ecomuseos y patrimonio cultural}

El territorio es un mosaico donde se interrelacionan seres vivos, pueblos y ciudades, infraestructuras y equipamientos, industrias y comercios, restos arqueológicos y paisajes naturales, todo lo cual conforma una estructura heterogénea en un determinado espacio y forma parte de un proceso cultural dinámico y en cambio permanente, que requiere apoyarse en una nueva visión de la cultura y en nuevos instrumentos de actuación (Troitiño, 2003).

Ahora bien, la cultura engloba diferentes concepciones (Hernández, 1989):

a) Como herencia a conservar y restaurar (ya que forma parte de un patrimonio o de una memoria colectiva).

b) Como componente de nuestra conciencia (con capacidad para crear, participar e innovar).

c) Como oferta de productos artísticos de consumo.

d) Como generador de riqueza e instrumento para crear un nuevo espacio de desarrollo.

Por ello, se han diseñado una serie de instrumentos (ecomuseos, equipamientos e infraestructuras culturales, parques culturales, planes de dinamización turística, programas de desarrollo local, planes estratégicos, etc.) que pueden utilizarse para la reutilización funcional del patrimonio (Maynard, 1985; Max Neef, 1994), no solamente «vendiendo» el patrimonio cultural, sino también valorizando los recursos existentes en un territorio, tanto para la comunidad local, como para la sociedad en general. Así, la promoción cultural debe de vincularse a los edificios y a los procesos productivos, a la creación de empleo, a la innovación tecnológica y a la generación de riqueza.

Sin embargo, este proceso, para obtener un éxito adecuado, debe acompañarse de una acción conjunta de los agentes locales y de los medios exógenos, privados y públicos, porque así el patrimonio cultural actúa como un importante recurso de cohesión y de reforzamiento de las señas de identidad, ya que la cultura posee unas funciones sociales que son importantes para el desarrollo de una comunidad, como la autoestima, los mecanismos de 
selección de las influencias exteriores y de la herencia del pasado, el desarrollo equilibrado de la colectividad y el dar sentido a las acciones que se realizan (Verhelst, 1994).

Ahora bien, esta revalorización del patrimonio, convirtiéndolo en recurso turístico mediante acciones de restauración o de rehabilitación, debe estar sujeta a una serie de limitaciones, ya que no se puede caer en el riesgo de convertir el territorio en un simple "espacio de mercancía», donde el turismo puede ser un importante motor de desarrollo o un factor de destrucción, por lo que no se debe pensar únicamente en propiciar la afluencia numérica de visitantes, sino también en considerar el placer cultural de las propias poblaciones locales, que ven como su herencia y su patrimonio se revalorizan, sin olvidar que, en ocasiones, una parte de los beneficios así obtenidos no siempre redundan en favor de la comunidad local (Troitiño, 2003).

Además, en las últimas décadas, la deslocalización industrial ha provocado, en los países más desarrollados, un desmantelamiento de sus industrias vinculadas a procesos de reconversión u obsolescencia funcional, lo cual ha generado grandes estructuras en el territorio que son susceptibles de rehabilitación para fines turísticos. Ello ha creado una arqueología industrial que ha generado una serie de problemas y reflexiones que abarcan una dimensión física y conceptual novedosa, de modo que se ha pasado de la mera exposición museística de máquinas aisladas a la exhibición de multitud de elementos interrelacionados con el territorio (infraestructuras, factorías, almacenes, canales, puentes, líneas ferroviarias, etc.) que explican los procesos industriales ocurridos y los paisajes asociados (Negri, 2007).

Siguiendo las pautas de este nuevo modelo, los ecomuseos se presentan como instrumentos de dinamización cultural, con una nueva lectura del territorio, más como «movimientos culturales» que como «equipamientos culturales», en el sentido tradicional del término (De Varine, 1985), es decir, cada vez son más «museos de ideas» en lugar de «museos de objetos».

Tanto el término como el concepto de ecomuseo son relativamente jóvenes, gracias a las exigencias filosóficas del International Council of Museums (ICOM) y, especialmente, de Georges Henri Riviére (1985), que actuó como catalizador de ideas, al dar las directrices y la coherencia necesarias para la realización de los distintos proyectos de los ecomuseos que surgieron entre 1967 y 1985.

En la definición más comúnmente aceptada (Rivière, 1985), se considera el ecomuseo como «instrumento que el poder político y la población conciben, fabrican y explotan conjuntamente [...] un espejo, donde la población se contempla para reconocerse, donde busca la explicación del territorio donde está enraizada [...] una expresión de los seres humanos y de la naturaleza [...] una escuela, en la medida que asocia la población a sus actividades de estudio y protección y la incita a tomar mayor conciencia de los problemas que plantea su propio futuro».

Bajo este prisma, el ecomuseo ayuda a reforzar la memoria colectiva y la identidad de la comunidad, actuando, además, como vehículo de cohesión y 
desarrollo de la sociedad, con una participación activa de la población local, no sólo como objeto del museo, sino también como encargada de conservar y mostrar ese patrimonio, junto con los profesionales de los museos, sustituyendo el concepto de «conservación» por el de «revitalización, gestión y difusión» del patrimonio cultural, y el de «musealización» por el de «interpretación del patrimonio» o habilidad de explicar el significado y la trascendencia de un lugar patrimonial a la gente que lo visita (Layuno, 2007).

Por su parte, para Peter Davis (2007), el ecomuseo se sitúa en el centro de tres esferas: las referentes al museo, al entorno y a la comunidad, mientras que para Maurizio Maggi y Vittorio Falletti (2000) el ecomuseo se basa en un pacto, con el que una comunidad se hace cargo de un territorio.

Para Jean Claude Duclos (1992), el concepto de ecomuseo engloba «una museografia del tiempo y del espacio, con el desarrollo como objetivo, la interdisciplinariedad como herramienta y la participación como motor», mientras que la Red Europea de los Ecomuseos (2007) lo define como «un proceso dinámico con el cual las comunidades preservan, interpretan y valoran su patrimonio para el desarrollo sostenible», de modo que un ecomuseo se funda en un acuerdo con la comunidad, y, por su parte, el Natural History Committee del ICOM (Engström, 2009) ha elaborado su propia definición, en la que dice que: «el ecomuseo es una institución que gestiona, estudia y valora - con finalidades científicas, educativas y, en general, culturales- el patrimonio general de una comunidad específica, incluido el ambiente natural y cultural del medio».

Así pues, el ecomuseo es un vehículo para la participación cívica en la proyección y en el desarrollo colectivo, y con este fin utiliza todos los instrumentos y los métodos a su disposición, con el objetivo de permitir al público comprender, juzgar y gestionar los problemas con los que debe enfrentarse. En esencia, podemos afirmar que utiliza el lenguaje y la realidad de la vida cotidiana y de las situaciones concretas con el fin de alcanzar los cambios deseados.

Así, del conjunto de estas definiciones, podemos extraer tres componentes comunes:

a) El propio museo (edificio, maquinaria y procesos).

b) El territorio (no sólo la superficie física, sino también los elementos ambientales, culturales y sociales que definen un patrimonio local determinado).

c) La comunidad y las instituciones locales (que son las que tienen el compromiso de ocuparse y desarrollar el futuro del territorio).

Los ecomuseos no solo ayudan a rescatar la memoria colectiva, sino que, por su relación con el territorio, se constituyen en vínculo entre pasado, presente y futuro. Así, en lo posible, deberían nacer y crecer por deseo de la propia comunidad, sin imposición por parte de agentes externos, que sólo deberían prestar apoyo profesional para organizarlos y ejercer la corresponsabilidad en todos los niveles de la comunidad (Guzmán y Fernández, 2003). 
Entre las principales ventajas que presentan los ecomuseos, siguiendo a Pardo (2004), podemos mencionar la recuperación de un pasado industrial y de un paisaje olvidados, la recuperación de una identidad local, la recuperación de una estética crecientemente valorada y que muchas veces solo se presenta con el cese de la actividad, la conservación completa, tanto interior como exterior de los espacios industriales, su uso público, dirigido tanto a los visitantes externos como a los residentes, el importante protagonismo de la comunidad local, con incorporación de experiencias personales de antiguos trabajadores, el desarrollo económico de áreas deprimidas y en declive industrial y, finalmente, su carácter didáctico.

En suma, los ecomuseos valorizan el patrimonio industrial y ayudan a difundir una nueva cultura del desarrollo sostenible del territorio, donde la memoria colectiva se convierte en el principal motor de unos programas que deben desenvolverse con la participación activa de la población local (Troitiño, 2003), aplicando las técnicas museográficas más didácticas y sensoriales, basadas en las nuevas tecnologías, a través de procesos de inmersión ambiental, lo cual da como resultado una participación activa en una experiencia lúdica y educativa (Layuno, 2007).

Esta búsqueda de nuevos vínculos con la comunidad local ya orientó la experiencia de los primeros ecomuseos, como puede ser el caso de Le CreusotMontceau-Les Mines, en el departamento de Saona y Loira, en la Borgoña, con problemas sociales y de despoblación, debido a la reconversión de las industrias de la minería y la siderurgia, y que se presenta como museo del ser humano y de la industria, según la definición dada por Hubert (1989): «la comunidad toda entera constituye un museo vivo donde el pueblo se encuentra permanentemente en su interior [...] El museo no tiene visitantes, tiene habitantes».

Por ello, la puesta en valor turístico de estos recursos patrimoniales debe servir para que los destinos puedan afrontar un importante reto: lograr la inserción equilibrada del turismo en la economía y en la sociedad, en el marco de unos modelos de desarrollo realizados con una estrategia global y multidisciplinaria, que permitan conciliar la conservación del patrimonio industrial, su utilización responsable y la dinamización funcional (Troitiño, 2000).

\section{El turismo del patrimonio industrial como fenómeno dinamizador del territorio}

En una sociedad postmoderna como la actual, donde la mayor parte de la población es urbana y se dedica al sector servicios, en los últimos años se han producido importantes cambios en el ámbito del turismo, puesto que han aumentado las exigencias de unos turistas con mayor experiencia, poder adquisitivo y disponibilidad de tiempo libre, lo que les convierte en grandes consumidores de bienes y servicios (Garay y Cànoves, 2009). Ello genera riqueza y empleo, directo e indirecto, para trabajadores, empresarios y 
Administración local, y aumenta las exigencias a los gestores implicados en las actividades turísticas para que adopten nuevas estrategias de atracción de unos visitantes para los que el ocio y la cultura son valores en alza (Borja, Jiménez y Sevilla, 2005).

Por ello, la progresiva reducción del ciclo de vida de los productos turísticos ha revolucionado los modelos de planificación territorial, con ofertas más flexibles y progresivas, que puedan compatibilizar la identidad del turismo con la capacidad de renovación constante de los territorios.

En este nuevo marco, ha aumentado el interés por el turismo industrial, como una alternativa para el desarrollo de territorios industriales deprimidos social y económicamente (al estar afectados por el cierre y el abandono de la actividad productiva) o como una oferta complementaria que ayude a otros turismos más tradicionales y consolidados, como el de sol y playa.

Con el turismo industrial, se ha creado la paradoja de una nueva identidad de los viejos espacios industriales, que fueron unos espacios proscritos durante buena parte del siglo pasado, al ser lugares de trabajo (rutinarios, despersonalizados, grises y monótonos), lo que, en la imaginación popular, equivale a considerarlos deshumanizados y concebidos como entornos al margen de la vida social y personal, y que en la actualidad se valoran como objetos turísticos que pueden ser consumidos como espacios de ocio, de recuperación cultural y de recreación.

En su análisis sobre el turismo postfordista, Urry (1990) ya identificó la importancia de dicha mutación social, territorial y simbólica, en la que los espacios periféricos de la industrialización eran absorbidos por la geografía del turismo, con lo que se produjo una refuncionalización de los espacios (los espacios industriales se han desprovisto de su condición inicial de ámbito productivo y ello ha provocado un cambio de uso, de significado y de interpretación, de modo que la reconversión social de su uso ha transformado su esencia de forma absoluta) y una reafirmación de la autenticidad (exceptuando las colonias industriales situadas a lo largo de los ríos, la mayoría de estos espacios nacieron como ámbitos desligados de los residenciales), por lo que el paisaje de la industrialización es, en esencia, un paisaje confrontado al espacio residencial y recreativo de los siglos pasados, con una estrategia basada en la fosilización «museizada» de sus contenidos, donde se preservan algunos elementos del pasado para un consumo turístico y recreativo, emparejado con una cierta representación teatral de las formas de vida y de los procesos industriales antiguos.

El turismo industrial ayuda a valorizar el entorno, la cultura y la sociedad, unificando los patrimonios industrial, natural y cultural (Cuadrado, 2006); reafirmando la identidad de la comunidad (Álvarez, 2003) y la continuidad de sus antecedentes industriales, técnicos, económicos, sociales y culturales (Gómez, 2002; Bergeron, 2003), y configurando el patrimonio industrial como un elemento básico de los paisajes y de la cultura del territorio (Pardo, 2004). Este proceso de potenciación de los restos materiales de la industrialización en su contexto espacial permite mostrar a la sociedad los vínculos existentes con el territorio (Benito, 2002). 
En consecuencia, el turismo industrial, con la comunidad local como protagonista (Andereck, 2005), engloba un conjunto de elementos interrelacionados (figura 1): territorio, patrimonio industrial y tareas y costumbres propias de la vida local, así como todas las actividades relacionadas directamente con el patrimonio y con la sostenibilidad del destino (Lee, 2005; Miller, 2010).

Aunque, inicialmente, la mayoría de las experiencias de turismo industrial se han asociado a proyectos de tipo educativo, no puede negarse su atractivo para el turismo cultural, dado que incorpora distintos procesos históricos de desarrollo económico, de evolución de las formas laborales y de los diferentes cambios socioculturales producidos en la sociedad por efecto de la urbanización fabril y de las nuevas tecnologías (Fernández y Guzmán, 2005).

En este nuevo marco, los ecomuseos colaboran decisivamente en el desarrollo de un territorio, ya que potencian el desarrollo equilibrado y sostenible de la comunidad, actúan como centro de identidad local, mediante la interpretación del presente y su transformación a partir del pasado, y estudian la relación existente entre el territorio y la comunidad, actuando como museo del espacio y del tiempo.

Ahora bien, a pesar de su indudable atractivo, no hay que olvidar que, en general, este tipo de turismo, debido a su limitada capacidad de atracción, no es la solución definitiva a los problemas de desarrollo de muchos territorios deprimidos, ya que, desde este punto de vista, existen otras formas de turismo con mayor efectividad al respecto, con beneficios más rápidos, mientras que, en el caso del turismo industrial, los beneficios son más a largo plazo, por lo que

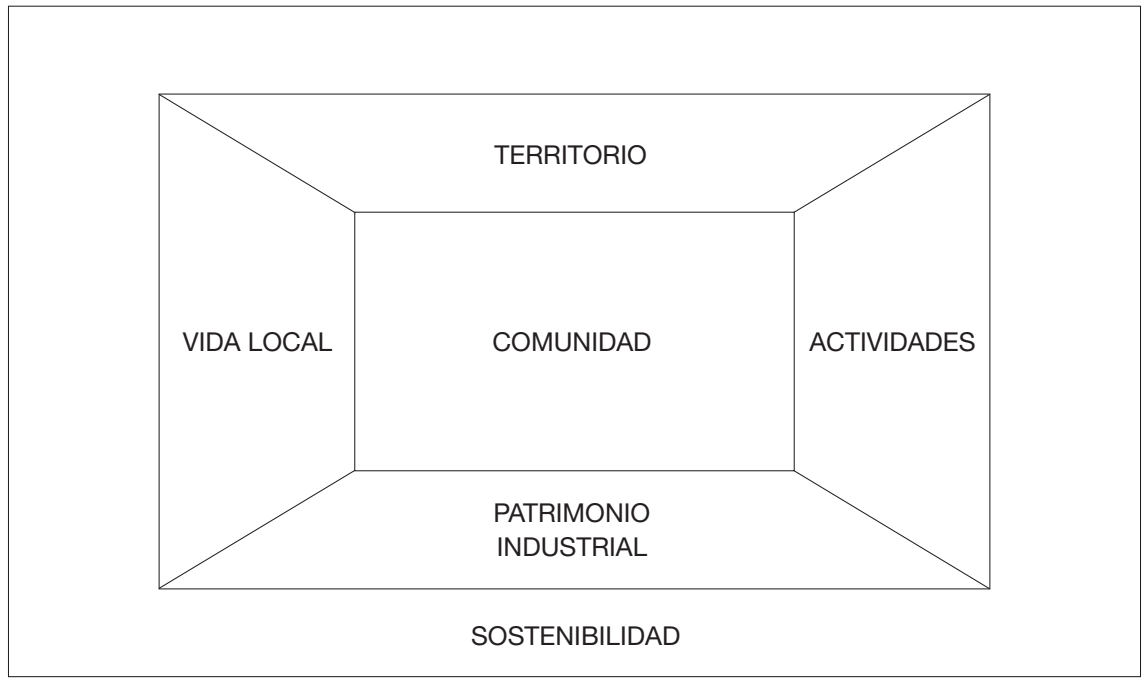

Figura 1. Esquema conceptual de turismo industrial.

Fuente: elaboración propia a partir de Lee, 2005, y Miller, 2010. 
éste tiene que estudiarse dentro de una estructura económica más diversificada (Llurdés, 1999).

En resumen, los ecomuseos son un soporte fundamental para la puesta en valor turístico y educativo del patrimonio industrial de un territorio, ya que el propio museo, con sus actividades, exposiciones, proyectos y servicios, sirve para explicar no solamente los procesos industriales antiguos, sino también su relación con la vida local y con el territorio, dentro de un entorno dinámico y cambiante, tal como se representa en el esquema siguiente (figura 2).

Este es, por tanto, un tipo de turismo que, salvo excepciones, está considerado por la población local como algo beneficioso, ya que, además de la creciente preocupación existente entre las asociaciones y las entidades locales para recuperar su patrimonio industrial, ejerce una importante función educativa y ayuda a reforzar el sentimiento de identidad local.

En el siguiente apartado, se presenta el caso del ecomuseo La Farinera, en la provincia de Girona, como ejemplo de museo integrado con el territorio que refleja su evolución social y económica, mediante la recuperación y la valorización turística de su patrimonio industrial, en este caso hidráulico y agroalimentario, y donde la cultura del agua también ayuda a corporeizar la propia configuración histórica del territorio (Lorente, 2006), que, al valorizarse turísticamente, no introduce nuevos hábitos ni formas de vida en la comunidad local, ni genera ninguna conflictividad entre visitantes y residentes.

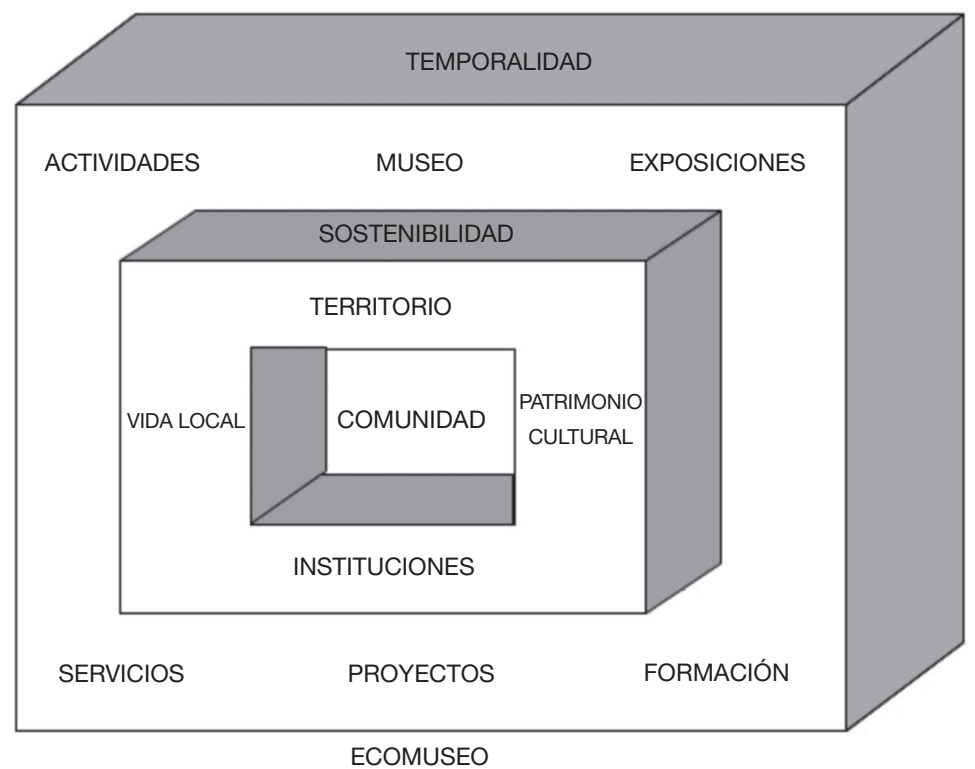

Figura 2. Esquema del concepto de ecomuseo.

Fuente: elaboración propia. 


\section{El ecomuseo La Farinera, de Castelló d'Empúries}

El municipio de Castelló d'Empúries está situado en la comarca del Alt Empordà, en la provincia de Girona (figura 3), con una altitud media de 17 metros sobre el nivel del mar, 12.220 habitantes, una superficie de $42,3 \mathrm{~km}^{2}$ (incluyendo el Parque Natural de Els Aiguamolls de l'Empordà) y una densidad de 288,9 hab. $/ \mathrm{km}^{2}$ (Idescat, 2010).

Los dos núcleos de población principales son Castelló d'Empúries, mencionado por vez primera en el año 879 y capital del condado medieval desde el siglo XI, y la moderna macrourbanización turística de Empuriabrava. Su estratégica situación, en medio de la planicie ampurdanesa, permite acceder rápidamente a la capital de la comarca, Figueres (a $16 \mathrm{~km}$ ), a Girona (a $54 \mathrm{~km}$ ) y a Barcelona (a $153 \mathrm{~km})$.

Se trata de un municipio donde el 15,47\% de la población es menor de 15 años, el 69,01\% tiene entre 15 y 64 años, y solamente el 15,52\% es mayor de

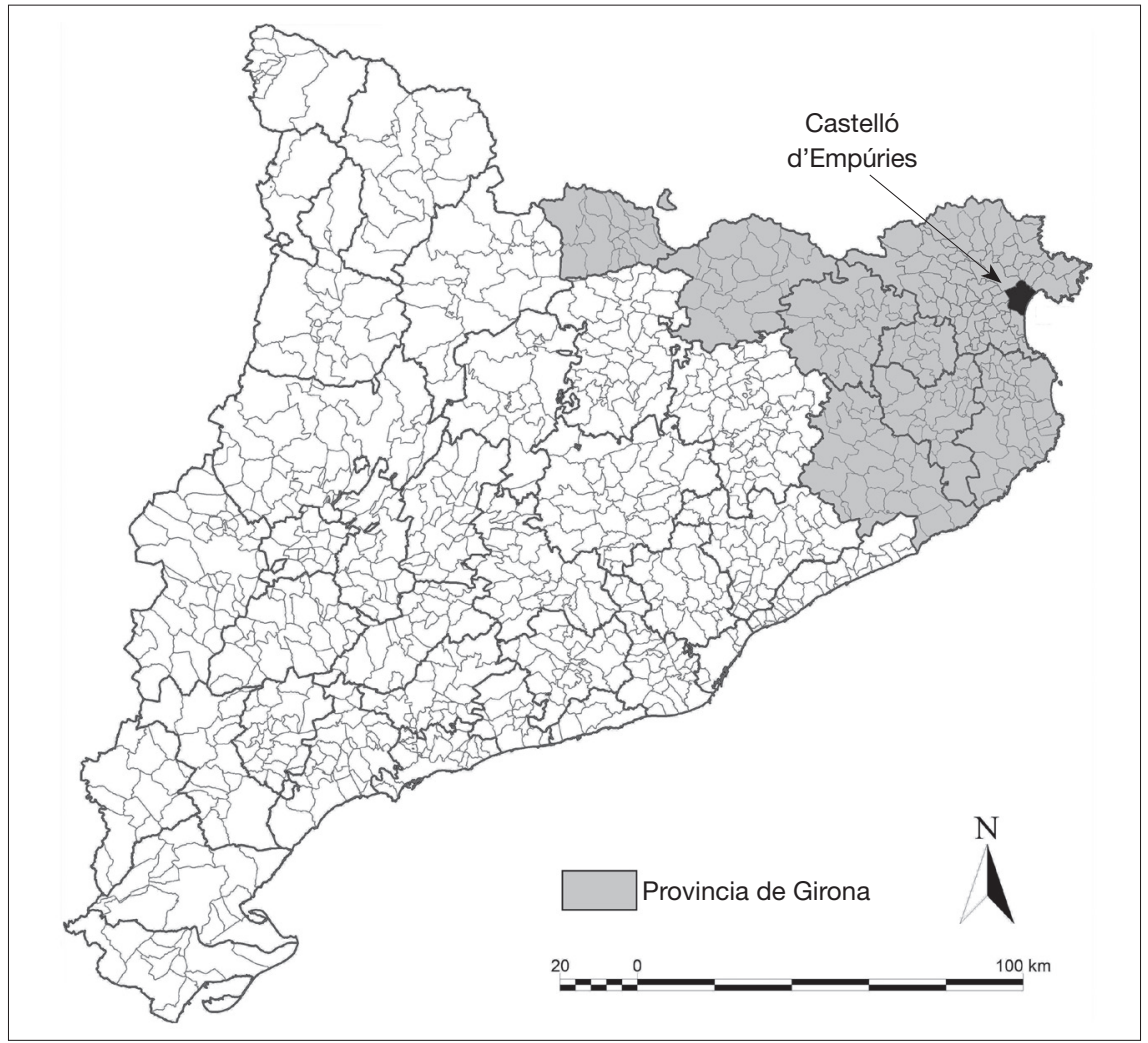

Figura 3. Mapa de situación.

Fuente: elaboración propia. 
64 años (Idescat, 2009). Una parte importante de su población es foránea, ya que el $49,75 \%$ ha nacido en el extranjero, e1 $11,07 \%$ en España pero fuera de Cataluña, y solamente el 39,18\% lo ha hecho en Cataluña (Idescat y Padrón de Población, 2009).

Su grado de movilidad laboral es relativamente bajo, ya que el 70,11\% de su población activa trabaja en el propio término municipal, mientras que el $29,89 \%$ restante lo hace fuera. Además, el $66,90 \%$ de la población activa que trabaja en el municipio reside en el mismo (Idescat, 2001).

A nivel económico, el valor añadido bruto $(\mathrm{VAB})$ por sectores de actividad (Idescat, 2006) muestra un claro predominio de los servicios (el 73,1\% del VAB municipal), seguidos por la construcción (el 20,1\%), la industria (el 5,8\%) y la agricultura (el 1\%), lo que contrasta con el predominio agrícola que había existido históricamente en este territorio hasta el desarrollo del turismo de litoral en el último cuarto del siglo pasado, con la creación de la marca turística Costa Brava.

Así, el empuje del sector terciario se manifiesta en que el 18,29\% de las empresas y de los profesionales del municipio se dedica al comercio minorista y el $54,39 \%$ a los restantes servicios. Destaca la presencia de más de 75 restaurantes (Idescat, 2002).

A nivel turístico, gracias a la atracción del núcleo residencial de Empuriabrava y a la proximidad de los núcleos costeros turísticos de Rosas y L'Escala, aunque se trata de un municipio muy pequeño (en el conjunto de la Costa Brava, solamente tiene el 1,08\% de su superficie y el 1,88\% de su población residente), dispone de 13 hoteles, con 1.418 alojamientos (el 1,90\% de la oferta total de plazas hoteleras en la Costa Brava), 5 campings, con 8.149 plazas ofertadas (el 7,79\% del total de la Costa Brava), y 5 establecimientos de turismo rural, con 47 plazas (el 1,58\% del total de la Costa Brava) (Idescat, 2010 y Observatori de Turisme, 2010).

También destaca la importancia de su turismo residencial, con 6.028 viviendas secundarias (el $44,35 \%$ del parque total de viviendas del municipio), 5.192 vacantes (el $38,20 \%$ ) y solamente 2.371 principales (el 17,45\%) (Idescat, 2001), lo que representa una ocupación estival mensual superior a los 75.000 habitantes.

\section{El ecomuseo La Farinera}

Se encuentra junto al núcleo medieval de Castelló d'Empúries, colindante con el antiguo monasterio de Santa Clara, la iglesia parroquial y las ruinas del castillo de los condes de Empúries.

Para ello, se ha restaurado un antiguo molino harinero, para dar a conocer el sistema de producción de la harina por métodos tradicionales, con una maquinaria de finales del siglo XIX y principios del $\mathrm{xx}$, incluyendo una turbina Francis, instalada en 1905 para generar energía eléctrica aprovechando el salto de agua del canal medieval (el Rec del Molí). Su objetivo principal es mostrar las relaciones económicas y sociales existentes entre el territorio y las comunidades que lo han habitado a lo largo del tiempo. 
Su valor añadido reside en su capacidad para reforzar el sentimiento de identidad de una comunidad con una importante presencia inmigratoria reciente, a través del conocimiento del desarrollo de una industria agroalimentaria, la harinera, basada en unas actividades agrícolas que, hasta fechas relativamente recientes, han sido de gran raigambre en el territorio ampurdanés. También ha servido para valorizar su antiguo patrimonio hidráulico, cuyos ingenios mecánicos transformaban la energía procedente del movimiento del agua para desarrollar diversas actividades, como la molienda, la generación de energía eléctrica para la iluminación de la población de Castelló, el riego de los huertos próximos y el abastecimiento de agua para el lavadero público, el abrevadero y el matadero municipales.

Para su gestación, construcción y mantenimiento como ecomuseo, desde el principio, bajo el impulso del Ayuntamiento de Castelló d'Empúries, han colaborado también diversas instituciones públicas y privadas, de las cuales destacan la comunidad local (a través de las asociaciones y entidades del municipio y de la comarca), la Unión Europea (con fondos FEDER), la Diputación de Girona, el Departamento de Cultura de la Generalitat de Catalunya, la Fundación "La Caixa" y muchos particulares a título individual, también se ha creado un patronato municipal para realizar su gestión.

El proyecto se ha desarrollado en varias fases. La primera se inició en 1995, mediante la adquisición municipal del edificio de la antigua harinera de finales del siglo XIX, edificado sobre otro molino más antiguo, así como del canal medieval, que, con un recorrido de $5 \mathrm{~km}$., desde Vilanova de la Muga hasta el estanque de Vilahut (en el Parc Natural dels Aiguamolls de l'Empordà), traía el agua al molino. En 1998, el ecomuseo abrió sus puertas al público, de forma limitada, ya que la completa restauración del edificio no finalizó hasta el 24 de julio de 2004 .

En el 2008, se inauguró la segunda fase, que afecta al edificio del Casal y al antiguo almacén. Se adecuaron estos espacios para oficinas, recepción de visitantes, tienda de recuerdos, salas de exposiciones temporales, zonas de talleres y sala polivalente (figura 4), dando la máxima importancia a la accesibilidad física en todas sus instalaciones, tema cada vez de mayor interés en el diseño de los museos (Molina y Cànoves, 2010).

Las siguientes fases, previstas para los próximos años, han de servir para crear un centro de interpretación, adecuar el huerto adyacente para usos didácticos y recuperar el canal medieval en su totalidad, de modo que el ecomuseo aún se encuentra en pleno proceso de desarrollo y rodaje.

Entre su oferta, podemos destacar las siguientes actividades:

a) Museo: las instalaciones de parte de la antigua harinera del siglo XIX, así como colecciones y donaciones particulares relacionadas con el proceso productivo de la harina y las relaciones con el entorno rural y medioambiental del territorio.

b) Exposiciones permanentes y temporales: relacionadas con el proceso productivo de la harina, la generación de energía y el patrimonio industrial. 
c) Formación: talleres y visitas guiadas para alumnos de primaria, infantil y secundaria, proyectos de investigación sobre algún aspecto del mundo harinero, prácticas para estudiantes universitarios, actividades pedagógicas de formación (dentro del Programa de Patrimonio Cultural y Educación de la Diputación de Girona) y difusión del patrimonio cultural entre los jóvenes (junto con el Consell Comarcal de l'Alt Empordà).

d) Servicios: un centro de documentación impresa y fotográfica, una tienda de recuerdos y productos locales, una web propia en Internet, una recepción y un aparcamiento gratuito de vehículos.

e) Otras actividades: visitas guiadas (individuales y colectivas), ferias del pan, la harina y el trigo, ecomercados (con productos locales, ecológicos y de calidad), jornadas monográficas y de puertas abiertas, como también la edición de publicaciones relacionadas con el ecomuseo.

Entre los proyectos de investigación, destacan un trabajo que se está realizando junto con la Universitat de Barcelona (UB), la Universitat Oberta de Catalunya (UOC) y el Instituto de Cultura de Barcelona, sobre la percepción social de la ciencia y la técnica mediante el patrimonio industrial y cultural (dentro del Programa Nacional de Fomento de la Cultura Científica y Tecnológica del Ministerio de Ciencia) y la participación en el proyecto De Itinere, Interreg III-A, entre Francia y España, para la puesta en valor del patrimonio

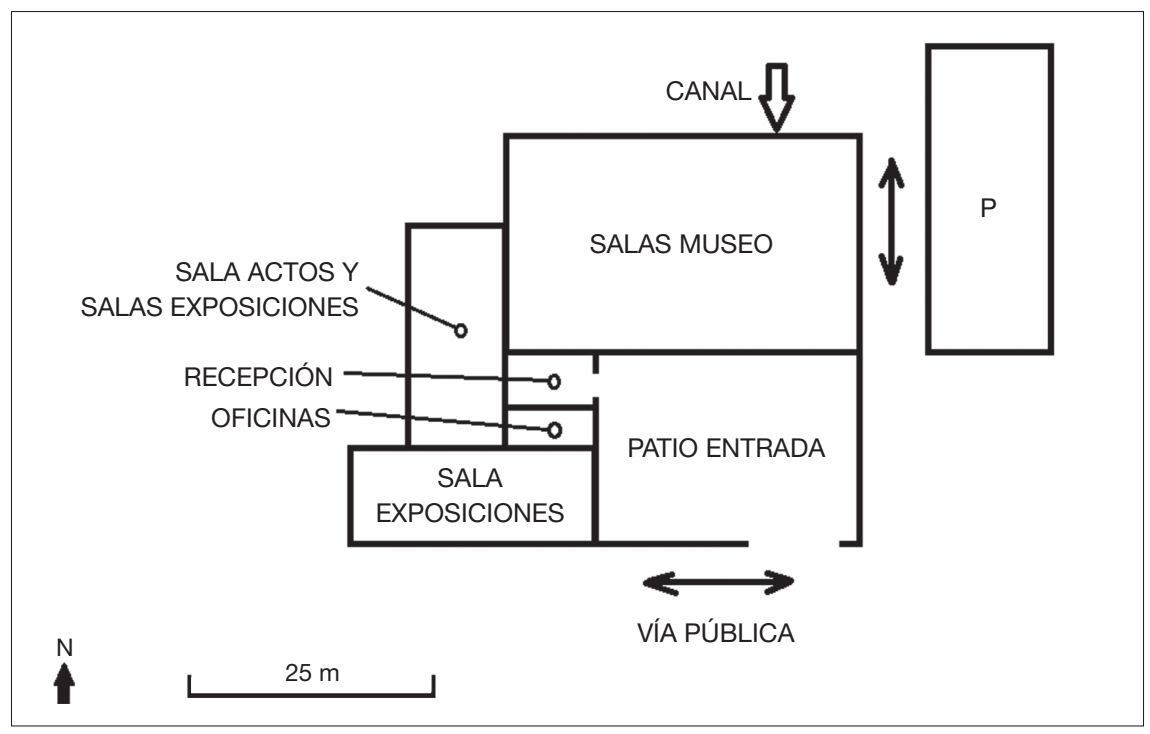

Figura 4. Situación del ecomuseo La Farinera de Castelló d’Empúries.

Fuente: elaboración propia. 
rural y cultural de los municipios de Mollet (Vallès Oriental), Elna (PyrénéesOrientales) y Castelló d'Empúries (Alt Empordà).

Además, forma parte del Sistema Territorial del Museo de la Ciencia y la Técnica de Catalunya (MNACTEC), compuesto por 25 museos de distintos aspectos temáticos, cuyo objetivo es explicar el proceso de industrialización en Cataluña y preservar su patrimonio industrial in situ. También es miembro de la Asociación XATIC (Red de Turismo Industrial de Catalunya), formada por 22 municipios con un importante legado industrial, cuyo principal objetivo es crear una línea de actuación común para la promoción del turismo industrial, dentro del Plan de Dinamización del Producto Turístico Industrial y de la Innovación Tecnológica de Cataluña.

Respecto al número de visitantes recibidos, en 2009 fueron 13.961, tal como puede apreciarse en el gráfico siguiente (figura 5), donde se presenta su evolución en el período 2005-2009. Predominan los visitantes provenientes de la propia Cataluña, aunque los extranjeros cada vez son más numerosos.

La evolución mensual de visitantes en este intervalo (figura 6) muestra una alta estacionalidad, con puntas de máxima afluencia en los meses de agosto, y una segunda punta en el mes de octubre, desde el año 2008, y que en el año 2009 ya ha superado el máximo de agosto. Los meses de menor afluencia, a lo largo de todo el período, son enero y febrero.

En el año 2009 (tabla 1), de los 13.961 visitantes recibidos, 8.445 (es decir, el 60,49\%) acudieron individualmente, mientras que los 5.516 restantes (el 39,51\%) fueron en grupo. El 2,55\% de ellos eran mayores de 65 años y

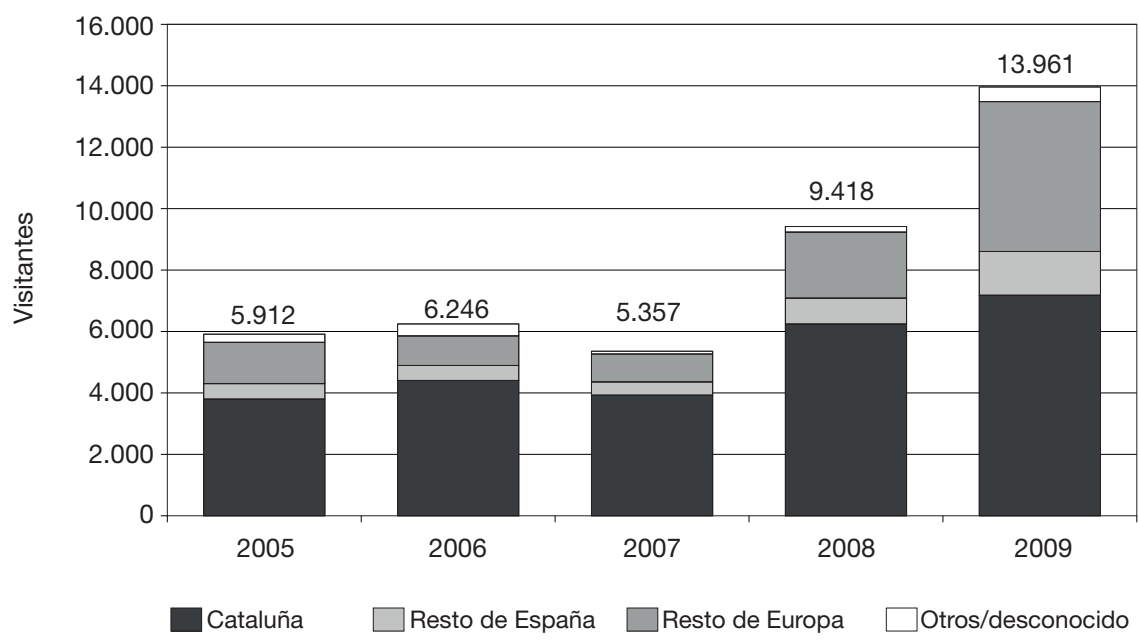

Figura 5. Evolución de la cantidad anual de visitantes del ecomuseo La Farinera por su origen (2005-2009).

Fuente: elaboración propia a partir de los datos facilitados por el Ecomuseo (2010). 
el 27,19\%, estudiantes menores de 16 años (en su mayoría provenientes de primaria y ESO).

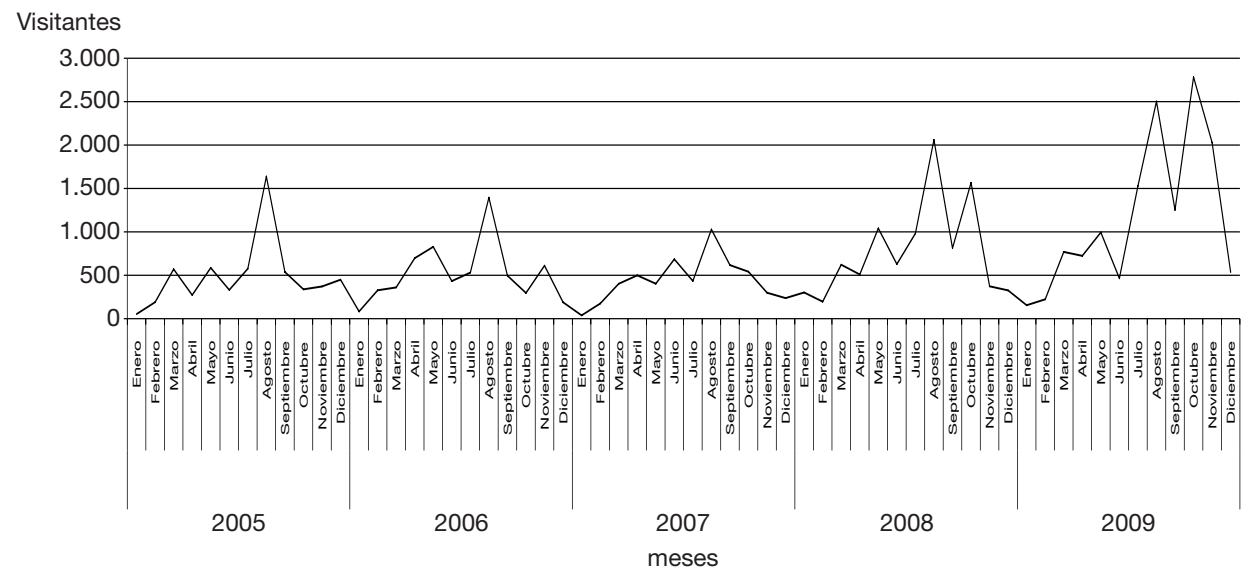

Figura 6. Evolución de la cantidad mensual de visitantes del ecomuseo La Farinera (20052009).

Fuente: elaboración propia a partir de los datos facilitados por el ecomuseo (2010).

Tabla 1. Estadística mensual de visitantes del Ecomuseo en el año 2009

\begin{tabular}{|c|c|c|c|c|c|c|c|c|c|c|}
\hline \multirow[b]{2}{*}{ Mes } & \multirow[b]{2}{*}{$\begin{array}{l}\text { Total } \\
\text { indiv. }\end{array}$} & \multicolumn{7}{|c|}{ Visitantes en grupo } & \multirow[b]{2}{*}{$\begin{array}{c}\text { Total } \\
\text { grupo }\end{array}$} & \multirow[b]{2}{*}{$\begin{array}{c}\text { Total } \\
\text { visitantes }\end{array}$} \\
\hline & & Infantil & Primaria & ESO & Bachillerato & Univers. & $\begin{array}{l}>65 \\
\text { años }\end{array}$ & Otros & & \\
\hline 1 & 68 & & & & & & 87 & & 87 & 155 \\
\hline 2 & 150 & & 48 & & & & & 25 & 73 & 223 \\
\hline 3 & 106 & 116 & 175 & 140 & & & & 232 & 663 & 769 \\
\hline 4 & 486 & & & 89 & 20 & & & 129 & 238 & 724 \\
\hline 5 & 539 & & & 80 & 57 & & & 318 & 455 & 994 \\
\hline 6 & 277 & & & & & & & 188 & 188 & 465 \\
\hline 7 & 1.102 & 109 & & 56 & & & 27 & 234 & 426 & 1.528 \\
\hline 8 & 2.229 & 24 & & & & & & 250 & 274 & 2.503 \\
\hline 9 & 947 & 12 & 10 & & & & & 283 & 305 & 1.252 \\
\hline 10 & 2.270 & 51 & 248 & 39 & 9 & & & 166 & 513 & 2.783 \\
\hline 11 & 137 & & 103 & 50 & & & & 1.739 & 1.892 & 2.029 \\
\hline 12 & 134 & & & 64 & & & 27 & 311 & 402 & 536 \\
\hline Total & 8.445 & 312 & 584 & 518 & 86 & 0 & 141 & 3.875 & 5.516 & 13.961 \\
\hline
\end{tabular}

Fuente: Ecomuseo, 2010. 
En cambio, en el año 2005 (tabla 2), de los 5.912 visitantes recibidos, 3.966 fueron individualmente (el 67,08\%) y los 1.946 restantes (el 32,92\%) lo hicieron en grupo. El 11,92\% de ellos eran mayores de 65 años y el 38,38\%, menores de 16 años.

Así pues, en este período han aumentado porcentualmente los visitantes en grupo en más de 6,5 puntos, aunque, relativamente, el porcentaje de mayores de 65 años y de estudiantes menores de 16 años ha disminuido. Aún así, la presencia de 1.500 estudiantes en grupo, en el año 2009, cifra que duplicaba la del año 2005 (747 estudiantes) no es nada desdeñable.

En cuanto a su lugar de procedencia, de los 13.961 visitantes del año 2009, 7.181 acudieron desde Cataluña (el 17,14\% lo hizo desde el propio municipio; el 13,20\%, desde otros municipios del Alt Empordà; el 22,25\%, desde el resto de la provincia de Girona; el 42,68\%, desde la provincia de Barcelona; el 3,35\%, desde la de Tarragona, y, solamente, el 1,38\% desde la de Lleida, lo que muestra la influencia de la distancia en las visitas); de las restantes comunidades autónomas fueron 1.240 visitantes y el resto (4.881) lo hicieron desde otros países europeos (figura 7).

Como vemos, la mayoría de los visitantes del año 2009 acudieron al ecomuseo desde la propia Cataluña, con predominio de los residentes en las provincias de Girona y Barcelona (entre las dos sumaron el 96\%), mientras que, de los que acudieron desde el resto de España, el 25\% fue desde Madrid, el 17\% desde Aragón y el 11\% desde el País Vasco. De los europeos, por proximidad geográfica, la mayoría fueron franceses (el 70\%), seguidos por los alemanes (el 11\%).

Tabla 2. Estadística mensual de visitantes del Ecomuseo en el año 2005

\begin{tabular}{|c|c|c|c|c|c|c|c|c|c|c|}
\hline \multirow[b]{2}{*}{ Mes } & \multirow[b]{2}{*}{$\begin{array}{l}\text { Total } \\
\text { indiv. }\end{array}$} & \multicolumn{7}{|c|}{ Visitantes en grupo } & \multirow[b]{2}{*}{$\begin{array}{c}\text { Total } \\
\text { grupo }\end{array}$} & \multirow[b]{2}{*}{$\begin{array}{c}\text { Total } \\
\text { visitantes }\end{array}$} \\
\hline & & Infantil & Primaria & ESO & Bachillerato & Univers. & $\begin{array}{l}>65 \\
\text { años }\end{array}$ & Otros & & \\
\hline 1 & 39 & & & & & & & 14 & 14 & 53 \\
\hline 2 & 109 & & 50 & & & & & 31 & 81 & 190 \\
\hline 3 & 224 & 85 & 126 & 26 & & & 40 & 69 & 346 & 570 \\
\hline 4 & 68 & & 47 & & & & & 157 & 204 & 272 \\
\hline 5 & 411 & & & & & & & 175 & 175 & 586 \\
\hline 6 & 176 & & 43 & & & 9 & & 103 & 155 & 331 \\
\hline 7 & 449 & & & & & & & 127 & 127 & 576 \\
\hline 8 & 1.567 & & & & & & & 71 & 71 & 1.638 \\
\hline 9 & 468 & & & & & & & 70 & 70 & 538 \\
\hline 10 & 214 & & 57 & 67 & & & & & 124 & 338 \\
\hline 11 & 126 & & 39 & 70 & & & 22 & 114 & 245 & 371 \\
\hline 12 & 115 & & & 137 & & & 170 & 27 & 334 & 449 \\
\hline Total & 3.966 & 85 & 362 & 300 & 0 & 9 & 232 & 958 & 1.946 & 5.912 \\
\hline
\end{tabular}

Fuente: Ecomuseo, 2010. 


\section{Cataluña}

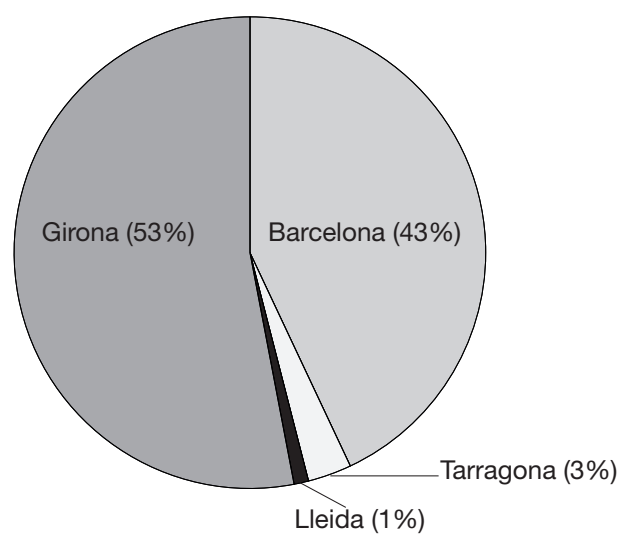

Resto de España

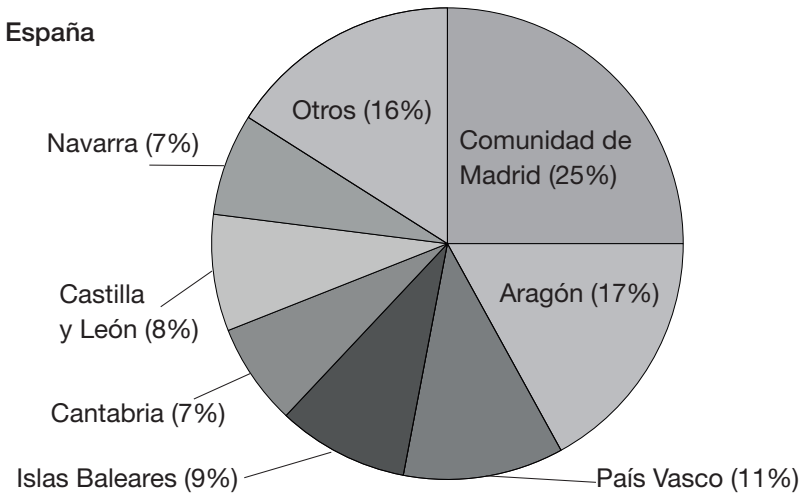

Europa

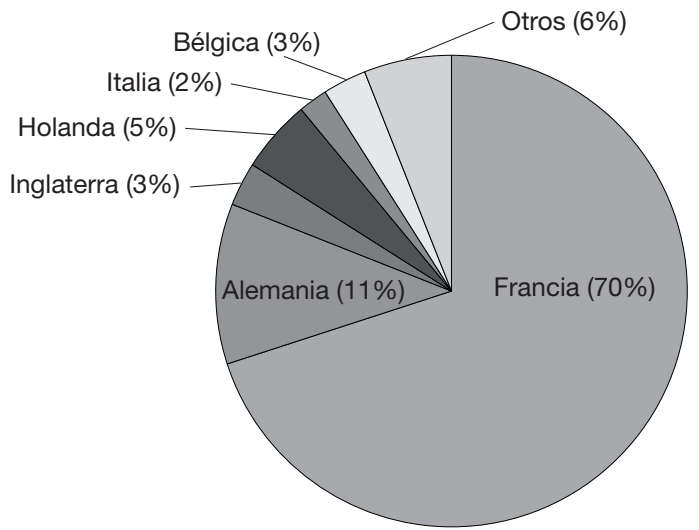

Figura 7. Origen en tanto por ciento de los visitantes del Ecomuseo provenientes de Cataluña, el resto de España y de Europa, en el año 2009.

Fuente: Ecomuseo, 2010. 
Respecto al grado de satisfacción de la visita, los resultados de una encuesta realizada por el propio ecomuseo en el año 2008, sobre una muestra de 3.225 visitantes no residentes en Castelló d'Empúries (lo que representaba el $35,25 \%$ del total). Tal como se puede comprobar en la tabla 3, los visitantes al ecomuseo no residentes en el municipio de Castelló d'Empúries concedieron una valoración muy alta a la visita (el $77 \%$ se manifestaron satisfechos o muy satisfechos) y el $2,8 \%$ dijo que repetía o que pensaba hacerlo. Solamente el $6 \%$ manifestaba una opinión negativa o regular. También es significativo que el 9,8\% de los visitantes manifestara su intención de volver a Castelló, aunque no al ecomuseo (seguramente para ver con tiempo suficiente la iglesia parroquial, las ruinas del palacio medieval y el casco antiguo del pueblo) y una gran mayoría (el 85,3\%) pensaba volver a la comarca ampurdanesa (seguramente gracias al tirón de la Costa Brava).

A nivel económico, en el año 2005, el ecomuseo obtuvo unos ingresos propios de 13.500 euros, con un presupuesto global de 230.000 euros (Terés, 2008). Aunque, en la actualidad, los ingresos directos se han duplicado debido al incremento del número de visitantes, la cuenta de explotación sigue siendo deficitaria, lo que obliga al patronato municipal, gestor del ecomuseo, a buscar subvenciones y patrocinios externos para compensar en lo posible el déficit existente.

Sin embargo, la presencia del ecomuseo ha permitido que, en el año 2009, 1.500 estudiantes menores de 16 años hayan visitado sus instalaciones, la mayoría realizando algunas de las actividades complementarias allí ofrecidas, así como 8.586 visitantes individuales o en grupos de mayores de 65 años.

Todo ello sin tener en cuenta el impacto económico producido por los visitantes en la comunidad local (restaurantes, bares y comercios), aprovechando sus visitas al ecomuseo y/o a Castelló d'Empúries.

Otro factor importante es que una parte significativa de estos visitantes (el $47 \%$, según la encuesta) son prescriptores para otros futuros visitantes.

Tabla 3. Resultados de la encuesta de 2008 sobre la repetición de las visitas y su grado de satisfacción

\begin{tabular}{lcc}
\hline Índice de repetición de visitas al ecomuseo & $2,8 \%$ \\
\hline Índice de repetición de visitas a Castelló d'Empúries & $9,8 \%$ \\
Índice de repetición de visitas al Alt Empordà & & $85,3 \%$ \\
Índice de recomendación de la visita a familiares y amigos & & $47 \%$ \\
\hline Grado de satisfacción de la visita al ecomuseo & Muy alto & $43 \%$ \\
& Alto & $34 \%$ \\
& Regular & $5 \%$ \\
& Bajo & $1 \%$ \\
\hline
\end{tabular}

Fuente: Ecomuseo, 2010. 
Ante esta situación, considerando el creciente interés por el turismo industrial, la cantidad potencial de visitantes que podría recibir el ecomuseo, con una buena oferta de exposiciones, conferencias y publicaciones, una intensa campaña publicitaria y una amplia colaboración con las entidades y las asociaciones locales y comarcales, escuelas, universidades y la Administración pública, podría ser, en pocos años, de unos 20.000 a 30.000 visitantes al año, de los que, siguiendo la progresión actual, estimamos que el $40 \%$ iría de manera individual y el 60\% restante en grupos (de los que, aproximadamente, un 25\% serían estudiantes).

Este incremento de visitantes, que duplicarían o triplicarían la cifra actual, aunque no sería muy significativo en valores absolutos (en un municipio de 12.000 habitantes censados y con más de 75.000 habitantes por mes en julio y agosto, sin tener en cuenta la cantidad global de turistas en la Costa Brava), sin duda ayudaría a desarrollar la economía local, ya que los visitantes individuales anuales (entre 8.000 y 12.000) y en grupos no estudiantiles (entre 9.000 y 13.000), a pesar de no realizar pernoctaciones en la zona, consumirían productos locales (restauración, comercios), sin contar las posteriores visitas exclusivas a Castelló.

Sin embargo, es un ecomuseo cuya génesis no ha partido estrictamente desde la comunidad local, sino desde algunas asociaciones y entidades, encabezadas por su ayuntamiento, que han visto que su realización podría servir para valorizar el patrimonio industrial, con unas claras potencialidades: situación geográfica en una zona muy turística, buena accesibilidad temporal, presencia de colecciones y exposiciones, buena presentación del sistema productivo de la harina, promoción a través de la red XATIC y del sistema mNACTEC, una website actualizada y acuerdos con escuelas y universidades, contrapesando otros puntos más débiles, como el endémico déficit presupuestario soportado, el poco personal cualificado disponible, una reducida visualización promocional del museo y la fuerte competencia de ofertas lúdicas en la misma zona (Terés, 2008).

En resumen, además de ser un factor de preservación del patrimonio industrial, de su faceta educativa y de ser un buen escaparate turístico del municipio, su mayor contribución, como ecomuseo, estriba en su ayuda a la reafirmación del sentimiento de identidad local, comarcal y regional, a través de las visitas guiadas, las actividades socioculturales y las exposiciones y los seminarios que se realizan periódicamente, teniendo en cuenta que es un municipio donde el $61 \%$ de su población no nació en Cataluña. Pero esta contribución identitaria no solamente se circunscribe a la población de la zona, sino que también se extiende al conjunto de la población catalana (gracias a los convenios escolares y a la promoción desde las redes XATIC y MANCTEC) y esta visión sociocultural se expande de Cataluña más allá de sus propias fronteras. 


\section{Conclusiones}

Los cambios que se han producido en los últimos años en el turismo han potenciado una amplia diversidad de oferta turística y una de estas nuevas ofertas es el turismo industrial, que se basa en la recuperación del patrimonio industrial.

El caso del ecomuseo de La Farinera nos ilustra cómo, a partir de un patrimonio industrial inicial, se conjuga la rehabilitación y la recuperación de los antiguos edificios e instalaciones industriales, la potenciación de la identidad local y la revalorización turística del municipio y sus alrededores. El ecomuseo sirve como catalizador para explicar los procesos productivos que allí se realizaban y las relaciones sociales que se establecían, así mismo, permite apreciar el entorno (tanto natural como urbano), poner el lugar en valor turístico y ayudar a dinamizar la economía local. Es a través del propio ecomuseo que los habitantes de Castelló d'Empúries contribuyen a revalorizar el sentimiento de identidad local y comarcal, lo que es muy importante en territorios con un alto nivel de inmigración, como ocurre en este caso.

El artículo ha mostrado que los ecomuseos no solo ayudan a rescatar la memoria colectiva, sino que, por su vinculación con el territorio, facilitan constituirse en un vínculo entre pasado, presente y futuro. En este sentido, no hay que olvidar que el desarrollo de un ecomuseo depende, habitualmente, del nivel de colaboración de la comunidad local, de las asociaciones y entidades y de los visitantes. En el caso de La Farinera, han sido los organismos públicos sus principales impulsores, conscientes de los beneficios que un ecomuseo puede comportar al territorio.

Tal como hemos anotado, un ecomuseo, y este es el caso de La Farinera, no suele ser una inversión rentable, ya que comporta altos costes iniciales para la compra y rehabilitación de edificios industriales y constantes costes de mantenimiento, con una renovación periódica de las actividades. Así mismo, la mejora de su gestión económica permitiría racionalizar la distribución de los escasos recursos económicos disponibles, por lo que sería aconsejable establecer correspondencias entre las subvenciones recibidas y el cumplimiento de determinados criterios (calidad en la gestión, número mínimo de visitas anuales, nuevos acuerdos con centros escolares, proyectos de investigación, etc.), y así poder obtener unos productos turístico-culturales vivos, con una buena oferta de actividades, con difusión suficiente y disponer de la colaboración del personal adecuado.

Finalmente, como se ha visto en el caso de La Farinera, se ha confirmado que el turismo industrial no es relevante y se presenta de forma muy esporádica, como una opción más de desarrollo territorial de un lugar en donde se disponen algunos recursos industriales. La falta de una red potente de ecomuseos integrados en el conjunto del turismo patrimonial y cultural hace de los casos aislados, como La Farinera, un producto más de visita turística, pero con escasa relevancia económica y social para el territorio donde se ubica. 


\section{Referencias bibliográficas}

Álvarez, M.A. (2003). «Industrias culturales y patrimonio industrial: Hacia un eje cantábrico en los itinerarios industriales europeos». En: Álvarez, M.A. Estructuras y paisajes industriales: Proyectos socioculturales y turismo industrial. Gijón: INCUNA, 15-39.

ANDERECK, K.L. et al. (2005). «Resident's perceptions of community tourism impacts». Annals of Tourism Research, 32 (4), 1056-1076.

Benito, P. (2002). «Patrimonio industrial y cultural del territorio». Boletín de la AGE, $34,213-227$.

Bergeron, L. (2003). «La valorización turística del patrimonio industrial». En: ÁlvaREZ, M.A. (coord.). Estructuras y paisajes industriales: Proyectos socioculturales y turismo industrial. Gijón: INCUNA, 9-13.

Borja, M.; Jiménez, J. y Sevilla, C. (coord.) (2005). Gestión del turismo cultural y de ciudad. Cuenca: Universidad Castilla-La Mancha.

Cuadrado, S. (2006). «Transformacions recents dels assentaments a la plana de l'Alt Empordà. Un exemple de noves dinàmiques d'urbanització a Catalunya». Documents d'Anàlsi Geogràfica, 48, 83-104.

Davis, P. (2007). «New museologies and the ecomuseum». En: Graham, B. y Howard, P. (ed.). Research Companion to Heritage and Identity. Ashgate.

Duclos, J.C. (1992). «Pour des musées de l'homme et de la société». Le Débat, 70, 174-176.

ENGSTRÖM, K. (2009). «The ecomuseum concept is taking root in Sweden». Museum International, $37,4$.

Fernández, G. y Guzmán, A. (2005). «Patrimonio industrial y rutas turísticas culturales: algunas propuestas para Argentina». Cuadernos de Turismo, 15, 97-112.

Garay, L.A. y CÀnoves, G. (2009). «El desarrollo turístico en Cataluña en los dos últimos siglos: una perspectiva transversal». Documents d'Anàlsi Geogràfica, 53, 29-46.

Gómez, J. (2002). «Patrimonio industrial y turismo industrial». En: Gestión del Patrimonio Industrial en la Europa del s. XXI. Bilbao: Congreso Vasco de Patrimonio Industrial, 215-221.

- (2006). Dos museologias: las tradiciones anglosajona y mediterránea: diferencias y contactos. Gijón: Trea.

Guzmán, A. y Fernández, G. (2003). Notas teóricas sobre los ecomuseos. Buenos Aires: Nueva Museología.

Hernández, A. (1989). Cultura y medio rural. Madrid: Narcea.

Hubert, F. (1989). «Histoire des écomusées». En: La Museologie selon George Henri Riviére. París: Dunod, 146-154.

ICOM - International Council of Museums (2009). «Natural History Committee». En: ENGSTRÖM, K. «The ecomuseum concept is taking root in Sweden». Museum International, 37, 4, 206-210.

ideSCAT - Institut d’Estadística de Catalunya (2001, 2002, 2006, 2009, 2010). www.idescat.cat.

Layuno, M.A. (2007). «El museo más allá de sus límites: Procesos de musealización en el marco urbano y territorial». Oppidum, 3. Segovia: Universidad SEK, 133-164.

LeE, C.K. et al. (2005). «Traditions of sustainability in tourism studies». Annals of Tourism Research, 32, 4, 1056-1076.

Lorente, M. (2006). «Patrimonio hidráulico». En: Comarca Ribera Alta del Ebro, $105-116$ 
LLuRdÉs, J.C. (1999). «Patrimonio Industrial y Patrimonio de la Humanidad. El ejemplo de las colonias textiles catalanas: Potencialidades turísticas y algunas reflexiones». Boletín de la AGE, 28, 147-160.

Maggi, M. y Falletti, V. (2000). Ecomuseums in Europe: What they are and what theycan be. Turín: Istituto Ricerche Economico-Sociali del Piemonte.

Max Neef, M. (1994). Desarrollo a escala humana. Madrid: Icaria.

Maynard, P. (1985). «La proclamación de la nueva museología». Museum, XXXVII, 200-201.

Menguin, J. y Masson, G. (1989). Guide du développement local et du développement social. París: L'Harmattan.

Miller, G. et al. (2010). "Public understanding of sustainable tourism». Annals of Tourism Research, 37 (3), 627-645.

Molina, M. y Cànoves, G. (2010). «Turismo accesible, turismo para todos: La situación en Cataluña y España». Cuadernos de Turismo, 25, 25-44.

Negri, M. (2007). "Territori e paesaggi dell'industria. Sistema e reti di musei dell'industria». En: Bıel, P. (coord.). Patrimonio Industrial y la Obra Pública. Actas. Jornadas. Zaragoza: Gobierno de Aragón. Consejería de Educación, Cultura y Deporte, 106-118.

Observatori de Turisme (2010). Catalunya Turística en xifres, 2009. Barcelona: Generalitat de Catalunya. Direcció General de Turisme. Departament d'Innovació, Universitats i Empresa.

PARdo, C. (2004). «La reutilización del patrimonio industrial como recurso turístico. Aproximación geográfica al turismo industrial». Treballs de la Societat Catalana de Geografía, 57, 7-32.

Red Europea de los Ecomuseos (2007). Proyecto VAGEM.

Rivière, G.H. (1985). "Definición evolutiva del ecomuseo». Museum, 148, 202-203.

- (1993). La museología: curso de museología. Textos y testimonios. Madrid: Akal.

Terés, M. (2008). El patrimoni industrial: conservació i musealització. El cas català. Treball de recerca del Master en Gestió del Patrimoni Cultural. Barcelona: Universitat de Barcelona.

Troitiño, M.A. (2000). «Ordenación del territorio y desarrollo territorial: La construcción de la geografía del futuro». En: Lecturas Geográficas: Homenaje a José Estébanez Álvarez. Madrid: Editorial Complutense, 628-642.

- (2003). «Patrimonio Cultural: Valorización económica y reutilización funcional». En: CULTURINNOVA2003. Jornadas de Gestión Cultural. La Palma.

URRY, J. (1990). The tourist gaze. Londres: Sage.

VArine, H. de (1985). «El Ecomuseo, más allá de la palabra». Museum, 148, 185. Santa Cruz de la Palma: Cabildo Insular de la Palma.

Verhelst, T. (1994). «Las funciones sociales de la cultura». Leader, 8, 10-11. 